MODELLING APPROACHES 



\title{
Modelling and forecasting monthly swordfish catches in the Eastern Mediterranean*
}

\author{
KONSTANTINOS I. STERGIOU ${ }^{1}$, GEORGE TSERPES ${ }^{2}$ and PANAGIOTA PERISTERAKI² \\ ${ }^{1}$ Laboratory of Ichthyology, Department of Zoology, Faculty of Sciences, Aristotle University of Thessaloniki, \\ 54006 Thessaloniki, P.O. Box 134, Greece, email: kstergio@bio.auth.gr \\ ${ }^{2}$ Institute of Marine Biology of Crete, P.O. Box 2214, 71003 Iraklion, Crete, Greece.
}

\begin{abstract}
SUMMARY: In this study, we used the X-11 census technique for modelling and forecasting the monthly swordfish (Xiphias gladius) catches in the Greek Seas during 1982-1996 and 1997 respectively, using catches reported by the National Statistical Service of Greece (NSSG). Forecasts built with X-11 were also compared with those derived from ARIMA and Winter's exponential smoothing (WES) models. The X-11 method captured the features of the study series and outperformed the other two methods, in terms of both fitting and forecasting performance, for all the accuracy measures used. Thus, with the exception of October, November and December 1997, when the corresponding absolute percentage error (APE) values were very high (as high as $178.6 \%$ ) because of the low level of the catches, monthly catches during the remaining months of 1997 were predicted accurately, with a mean APE of 12.5\%. In contrast, the mean APE values of the other two methods for the same months were higher (ARIMA: 14.6\%; WES: 16.6\%). The overall good performance of X-11 and the fact that it provides an insight into the various components (i.e. the seasonal, trend-cycle and irregular components) of the time series of interest justify its use in fisheries research. The basic features of the swordfish catches revealed by the application of the X-11 method, the effect of the length of the forecasting horizon on forecasting accuracy and the accuracy of the catches reported by NSSG are also discussed.
\end{abstract}

Key words: forecasting, X-11 census technique, uncertainty, long-term changes, Xiphias gladius, Eastern Mediterranean, Aegean Sea.

\section{INTRODUCTION}

The swordfish (Xiphias gladius) is a highly exploited cosmopolitan species in the Atlantic Ocean and the Mediterranean Sea. Fishing pressure on the different swordfish stocks has increased dramatically in the last twenty years because of its high market demand. In the Mediterranean Sea, where it has been exploited using harpoons and driftnets at least since Roman times, the annual swordfish catches increased sharply from about $4000 \mathrm{t}$ in 1976 to $20000 \mathrm{t}$ in 1988 (Anonymous, 1999). Since then, annual catches fluctuated between 12000 and $16000 \mathrm{t}$ and are mainly

\footnotetext{
*Received December 6, 2000. Accepted May 22, 2002.
}

composed of juveniles (Rey et al., 1987; Di Natale, 1990; Tserpes, 1995). The increasing trend in the reported catches could to some extent be attributed to the improvement of the fisheries statistics collection systems as well as to the intensification of fishing effort and exploitation of new fisheries.

Several aspects of the swordfish biology and stock structure have been studied in the Mediterranean Sea (De Metrio and Megalofonou, 1987; De Metrio et al., 1989; Tsimenides and Tserpes, 1989; Tserpes and Tsimenides, 1995), in which it forms a unique stock, distinct from the Atlantic ones (Kotulas et al., 1995).

As the available time series of fisheries and biological data are rather short and incomplete, they are unable to support concrete assessment studies and 
give reliable information on the demographic structure of the stock. However, the fact that juveniles dominate the catches suggests that the Mediterranean stock may be over-exploited. The same was also supported by a preliminary stock assessment study carried out by ICCAT scientists (Anonymous, 1996). The above findings have urged the International Commission for the Conservation of Atlantic Tunas (ICCAT) to recommend immediate measures for the conservation of the stock and the European Union to establish a minimum landing size of 120 $\mathrm{cm}$ LJFL in the Mediterranean Sea.

The Greek swordfish fishery started in the early 1980s and developed rather rapidly. Fishing is carried out using drifting longlines, mostly during February to September, in the eastern Mediterranean (Fig. 1). ICCAT records indicate that Greece is an important swordfish producer in the Mediterranean Sea (Anonymous, 1999).

In this study, we used the $\mathrm{X}-11$ census technique (Stellwagen and Goodrich, 1993) to model and forecast the monthly reported catches of swordfish in Greek waters during 1982-1997. Forecasts built with $\mathrm{X}$-11 were also compared with those derived from ARIMA (Box and Jenkins, 1976) and Winter's (1960) exponential smoothing models. The X-11 technique has recently been used to forecast the monthly anchovy catches in Greek waters (Stergiou, 2000), and a non-linear version of the X-11 method has also been used for the decomposition of oceanographic (Durand and Mendelsshon, 1998) and recruitment time series (Lloret et al., 2000).

\section{MATERIAL AND METHODS}

Fisheries statistics for Greek waters have been recorded since January 1964 by the National Statistical Service of Greece (NSSG, 1965-1999; Stergiou et al., 1997a). For a better evaluation of the available data, the waters fished by the Greek vessels have been divided into 18 statistical fishing subareas. Catch data are collected directly from a sample of fishing vessels that are surveyed by local customs authorities (stratified random sampling). For each vessel surveyed, a statistical questionnaire is completed showing the quantities of each major fish species (or group of species) caught during the previous month (or that the vessel did not work during that period). Although NSSG data suffer from various biases, which are higher for inshore fisheries, and the degree of bias cannot be easily estimated, they are the best figures available with respect to: (a) length of time, (b) spatial and temporal resolution, (c) consistency and degree of subjectivity in data collection, and (d) statistical design of data collection (Stergiou et al., 1997a).

Separate monthly catch data for swordfish are available only since 1982 (Table 1). In this study, we modelled the monthly reported swordfish catches for the years 1982-1996 and then built monthly forecasts for 1997 using the X-11 technique, which consists of a complex sequence of moving averages, seasonal moving averages, ratios to moving averages, outlier detection and removal procedures, and trading day regressions (Stellwagen and Goodrich,

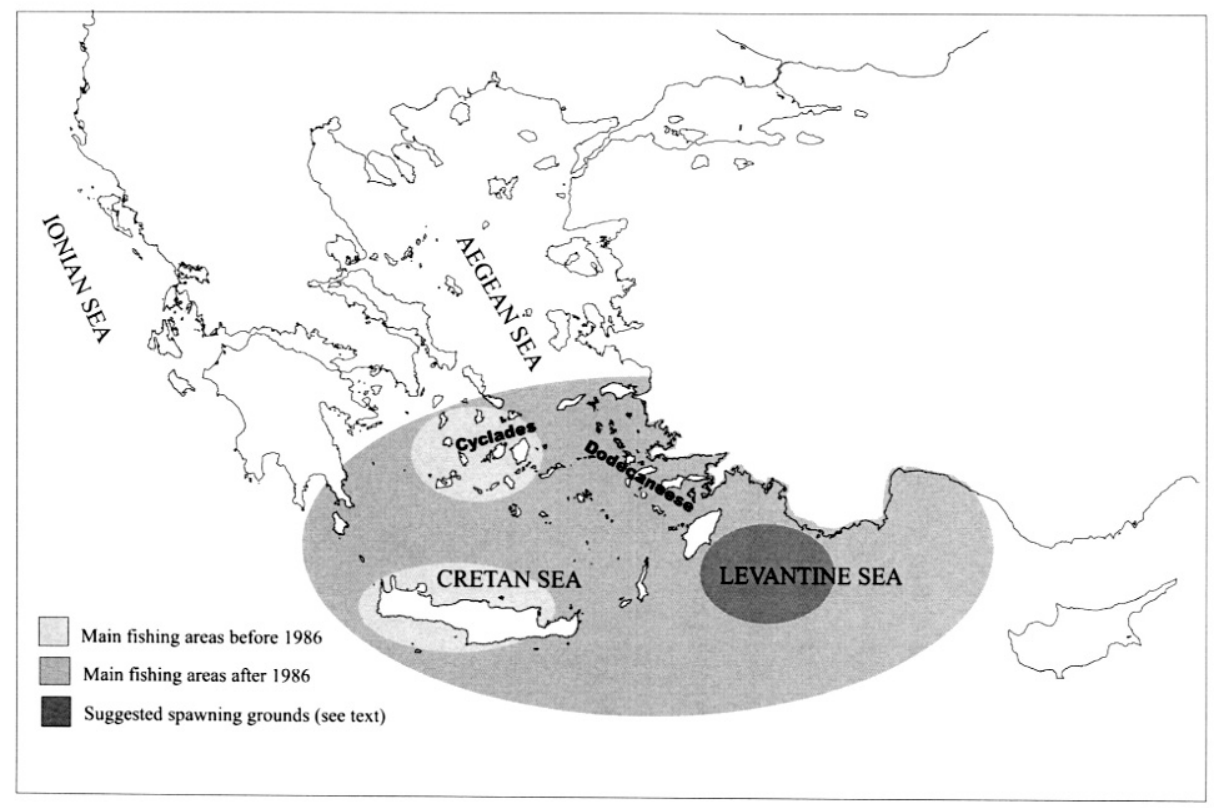

FIG. 1. - Fishing and spawning grounds of the swordfish, Xiphias gladius, in the Greek Seas. 
TABLE 1. - Monthly catches (in t) of swordfish in Greek waters, 1982-1997.

\begin{tabular}{|c|c|c|c|c|c|c|c|c|c|c|c|c|}
\hline & Jan & $\mathrm{Feb}$ & Mar & Apr & May & Jun & Jul & Aug & Sep & Oct & Nov & Dec \\
\hline 1982 & 36.1 & 28.5 & 75.9 & 62.5 & 63.3 & 65.8 & 55.4 & 66.0 & 53.6 & 24.1 & 14.6 & 9.6 \\
\hline 1983 & 133.4 & 7.9 & 17.2 & 27.8 & 28.9 & 37.5 & 44.5 & 60.7 & 55.1 & 19.2 & 9.8 & 13.0 \\
\hline 1984 & 19.7 & 16.1 & 26.8 & 38.6 & 92.4 & 130.4 & 118.1 & 111.4 & 87.1 & 67.7 & 39.2 & 24.7 \\
\hline 1985 & 40.1 & 35.7 & 106.5 & 122.3 & 126.8 & 138.4 & 105.7 & 152.4 & 138.7 & 70.6 & 42.7 & 29.9 \\
\hline 1986 & 48.6 & 75.5 & 108.0 & 123.8 & 153.4 & 187.1 & 226.8 & 149.0 & 142.5 & 63.6 & 48.0 & 29.7 \\
\hline 1987 & 30.4 & 62.5 & 77.3 & 80.8 & 84.4 & 117.8 & 125.5 & 113.9 & 107.5 & 69.1 & 24.4 & 24.0 \\
\hline 1988 & 43.3 & 105.2 & 84.6 & 110.0 & 133.6 & 147.4 & 161.2 & 177.3 & 156.4 & 63.9 & 35.4 & 32.9 \\
\hline 1989 & 98.2 & 199.2 & 178.7 & 233.7 & 183.8 & 241.2 & 322.4 & 288.9 & 185.7 & 75.1 & 21.3 & 2.4 \\
\hline 1990 & 34.7 & 86.0 & 96.2 & 96.7 & 125.8 & 153.8 & 170.2 & 223.2 & 159.6 & 32.6 & 20.5 & 15.5 \\
\hline 1991 & 71.6 & 129.5 & 100.9 & 164.4 & 101.1 & 97.2 & 145.4 & 195.3 & 202.5 & 21.3 & 22.8 & 25.6 \\
\hline 1992 & 50.0 & 138.6 & 103.4 & 90.7 & 94.1 & 65.6 & 136.4 & 165.2 & 86.2 & 30.9 & 33.1 & 37.3 \\
\hline 1993 & 21.3 & 55.9 & 57.7 & 52.1 & 47.6 & 54.6 & 116.2 & 223.8 & 228.4 & 24.1 & 9.7 & 1.0 \\
\hline 1994 & 21.2 & 128.4 & 157.8 & 99.2 & 201.2 & 293.9 & 283.3 & 284.1 & 212.3 & 45.5 & 2.5 & 4.9 \\
\hline 1995 & 13.9 & 209.7 & 162.6 & 146.0 & 213.0 & 158.0 & 180.0 & 171.0 & 114.0 & 20.0 & 5.3 & 8.9 \\
\hline 1996 & 16.0 & 126.0 & 98.0 & 101.0 & 179.0 & 164.0 & 155.0 & 164.0 & 164.0 & 18.0 & 23.0 & 28.0 \\
\hline 1997 & 30.0 & 173.0 & 137.0 & 114.0 & 159.0 & 220.0 & 247.0 & 267.0 & 157.0 & 28.0 & 15.0 & 7.0 \\
\hline
\end{tabular}

1993). The X-11 technique was developed by the US Department of Census and put into official use in October 1965 (Stellwagen and Goodrich, 1993). Its primary purpose was to deseasonalise national economic data in order to determine the underlying trend-cycle. The method extracts the following time series components from the original series $X_{t}$ : (a) the seasonal component $S_{t}$, (b) the trend-cycle component $\mathrm{C}_{\mathrm{t}}$, and (c) the random component $\mathrm{I}_{\mathrm{t}}$. The X-11 model has multiplicative and additive versions. In the multiplicative version, the components are multiplied to provide the original series, $X_{t}=\left(S_{t}\right)\left(C_{t}\right)\left(I_{t}\right)$, while in the additive version, they are added, $\mathrm{Y}_{\mathrm{t}}=\mathrm{S}_{\mathrm{t}}+\mathrm{C}_{\mathrm{t}}+\mathrm{I}_{\mathrm{t}}$. The $\mathrm{S}_{\mathrm{t}}$ indices are similar to those from the exponential smoothing methods, except that in the middle of the series they are based on complex weighting patterns of the observations both before and after the date of the observation. At the end of the series, the seasonal indices are based entirely on past data. The $\mathrm{C}_{\mathrm{t}}$ component consists of the underlying smooth changing level of $\mathrm{X}_{\mathrm{t}}$ and corresponds to the level of the exponential smoothing models. Finally, the $I_{t}$ component consists of the part of $X_{t}$ that cannot be explained by $S_{t}$ and $C_{t}$. A full account of the $\mathrm{X}-11$ technique is provided in Makridakis et al. (1983) and Stellwagen and Goodrich (1993).

In the present study, the X-11 technique, the additive version of which was applied on the original untransformed data, was used to decompose the monthly swordfish catches into the three components. Fits and forecasts were then developed for each of the three components separately (for $\mathrm{S}_{t}$ by repeating the last available monthly values, for $C_{t}$ by extending the local trend-cycle at the end of the series and for $\mathrm{I}_{\mathrm{t}}$ by setting all 0.0). Consequently, fits for 1982-1996 and forecasts for 1997 were estimat- ed by adding the individual fits and forecasts and were compared with the actual catches during both periods as well as with those derived from an ARIMA model (Box and Jenkins, 1976) applied on square-root transformed data, and a Winters' (1960) exponential smoothing (WES) model, applied on untransformed data. Both ARIMA and WES models perform very well for monthly fisheries time series (for an extended account of these techniques, see Stergiou et al., 1997b). In addition, X-11 was also fitted to the catches of the 1982-1993, 1982-1994 and 1982-1995 periods and forecasts were built for 1994-1997, 1995-1997 and 1996-1997 (i.e. 48, 36 and 24 forecasts in advance). All models were developed using Forecast Pro (Stellwagen and Goodrich, 1993).

Because all measures of accuracy suffer from advantages and disadvantages, a suite of such measures was used to compare fits and forecasts built with the different models with the actual catches during the fitting and forecasting periods (for an extended discussion see Stergiou and Christou 1996; Stergiou et al. 1997b): (a) the absolute percentage error (APE); (b) the mean APE (MAPE); (c) the root mean squared error (RMSE); (d) the coefficient of determination $\mathrm{r}^{2}$ between actual and fitted/forecasted series; and (e) the Ljung-Box (1978) statistic, which is used to indicate whether the errors are autocorrelated or not. The above-mentioned measures are very effective at capturing various aspects of modelling and forecasting accuracy (Stergiou and Christou, 1996; Stergiou et al., 1997b).

From the point of view of the practitioner forecaster, who is mainly accuracy-oriented, the success of a specific method can be judged by comparison with other methods (a naive included) (Makridakis 
et al., 1983). Thus Theil's (1966) U statistic was also used for evaluating forecasts. $U$ is defined as follows:

$$
U=\sqrt{\frac{\sum_{t=1}^{n-1}\left[\frac{e_{t}+1}{X_{t}}\right]^{2}}{\sum_{t=1}^{n-1}\left[\frac{X_{t+1}-X_{t}}{X_{t}}\right]^{2}}},
$$

where $e_{t+1}$ is the error at time $t+1$. $\mathrm{U}$ is a compromise between standard and relative measures (Stergiou et al., 1997b; Makridakis et al., 1983). It provides a measure of comparison of a given method with a naive method that uses as a forecast at time $t+1\left(=X_{t+1}\right)$ the catch at time $t\left(=X_{t}\right)$. $U$ attains values $>0 ; U>1$ indicates poor forecasting efficiency since the naive method produces better forecasts; $U<1$ indicates good forecasting efficiency.

\section{RESULTS}

The swordfish reported catches rose from about $500 \mathrm{t}$ in 1982 to a maximum of $2030 \mathrm{t}$ in 1989 and declined thereafter (Fig. 2). The monthly catches during 1982-1997 are shown in Figure 3a and the different components extracted using $\mathrm{X}-11$ are shown in Figures 3b-d. The $S_{t}$ component (Fig. 3b) clearly depicted the marked seasonality of the catches, being bimodal for the years 1982-1985, unimodal for 1986-1990 and bimodal again for the remaining years, especially for the last ones. The $\mathrm{C}_{t}$ component (Fig. 3c) clearly showed that catches exhibit a long-term increasing trend during the study period with cycles of about 2-4 years being superimposed on the long-term trend. Finally, the $I_{t}$ component exhibited higher variability for the years following 1991 (the coefficient of variation was

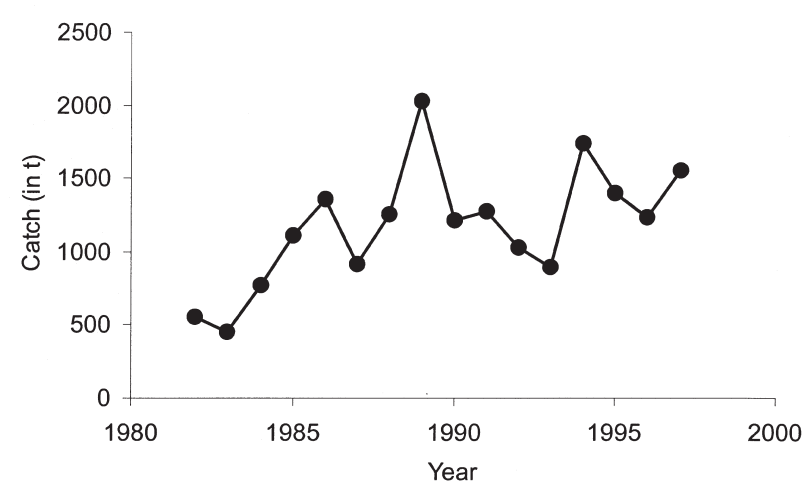

FIG. 2. - Annual reported catches of Xiphias gladius, Greek Seas, 1982-1997.
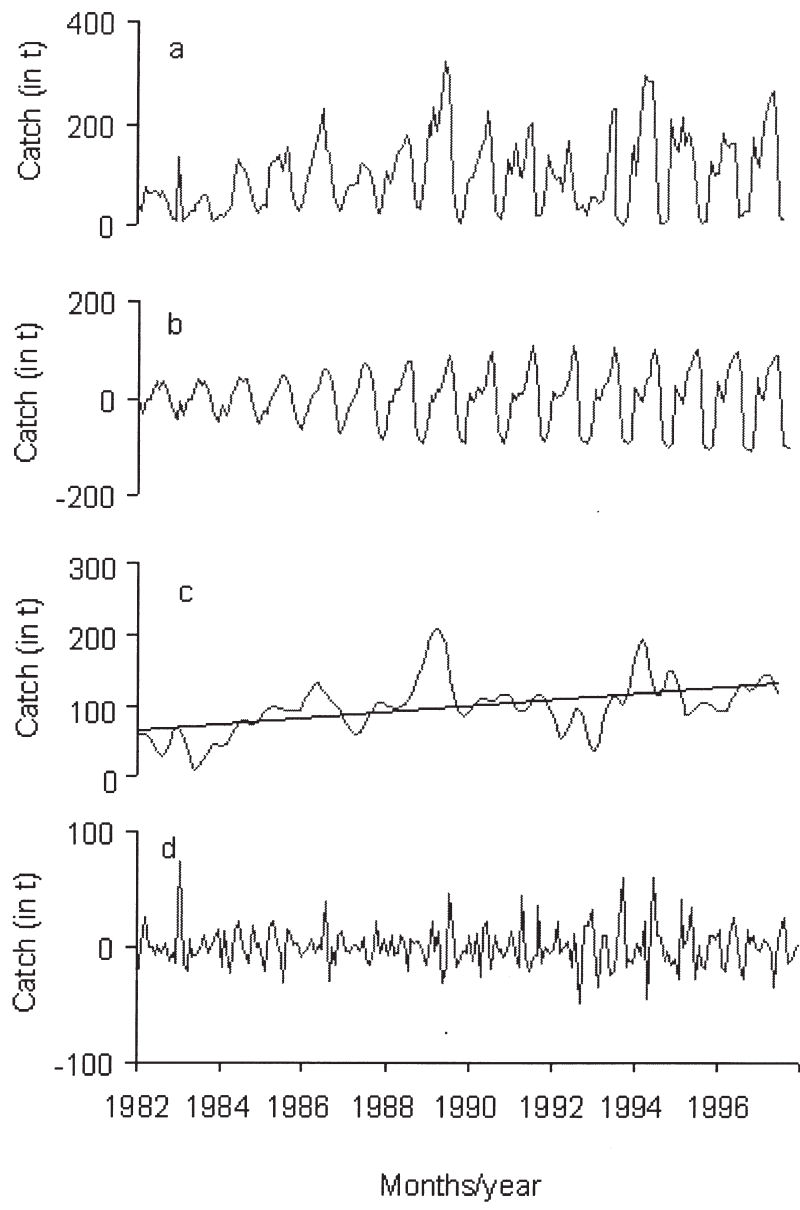

FIG. 3. - (a) Monthly catches of Xiphias gladius in the Greek Seas, and separation of catches into different components using the X-11 technique: (b) seasonal component, (c) trend-cycle component and (d) irregular component.

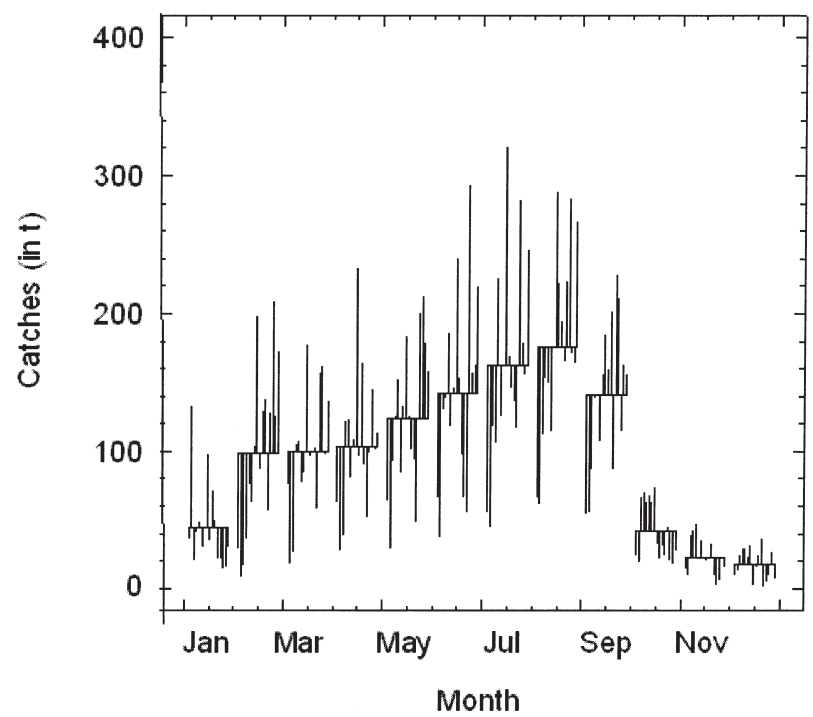

FIG. 4. - Seasonal sub-series plot of the monthly catches of Xiphias gladius, Greek Seas, 1982-1997. For each month, the horizontal line represents the mean catch over the 1982-1997 period and the vertical lines show the actual catches for each year of the 1982-1997 period. 
TABLE 2. - Arithmetic values of the different measures of accuracy used for the evaluation of the performance of the different models used for fitting, during 1982-1996, and forecasting, for 1997, of the monthly swordfish catches in Greek waters: (a) ARIMA $(1,0,0)(0,1,1)$ model, with coefficients $\mathrm{a}_{1}=0.6738, \mathrm{~B}_{12}=0.6209$; (b) Winters' exponential smoothing (WES) model, with additive seasonality and coefficients for level, trend and seasonality equaling $0.541,0.002$ and 0.770 respectively; and (c) X-11 model. $\mathrm{r}^{2}$ : coefficient of determination between fitted/forecasted catches and actual catches; APE: absolute percentage error; MAPE: mean APE; RMSE: root mean squared error; LB: LjungBox statistic (numbers in parentheses show the degrees of freedom and significant, $\mathrm{P}<0.05$, values are marked with an asterisk).

\begin{tabular}{|c|c|c|c|c|}
\hline Model & Accuracy measure & $\mathrm{X}-11$ & $\begin{array}{c}\text { Model } \\
\text { WES }\end{array}$ & ARIMA \\
\hline \multirow[t]{4}{*}{ Fits } & $r^{2}$ & 0.94 & 0.72 & 0.77 \\
\hline & RMSE & 17.6 & 37.2 & 35.8 \\
\hline & MAPE & 35.7 & 86.8 & 55.1 \\
\hline & LB (18) & $98.57^{*}$ & $45.6^{*}$ & 20.5 \\
\hline \multirow[t]{7}{*}{ Forecasts } & $r^{2}(10)$ & 0.95 & 0.88 & 0.92 \\
\hline & RMSE & 23.1 & 36.3 & 34.3 \\
\hline & Monthly APE range & 3.8-178.6 & $3.8-308.4$ & $2.1-115.7$ \\
\hline & MAPE & 31.8 & 50.1 & 22.2 \\
\hline & MAPE (excluding October-December) & 12.5 & 16.6 & 14.6 \\
\hline & Annual APE & 1.40 & 7.6 & 12.1 \\
\hline & U & 0.39 & 0.34 & 0.18 \\
\hline
\end{tabular}

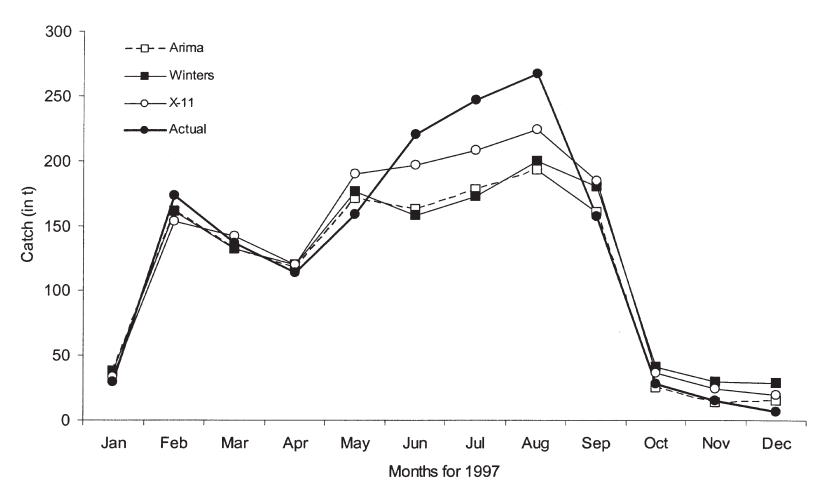

FIG. 5. - Comparison of the actual monthly catches of Xiphias gladius in 1997 with the forecast catches built with the X-11, ARIMA and Winter's techniques.

$115.7 \%$ and $258.4 \%$ before and after 1991). The seasonal pattern of the catches is also clearly depicted in Figure 4, with mean monthly catches increasing from a minimum of about 20-40 $t$ in OctoberJanuary to about $180 \mathrm{t}$ in August.

The various measures of fitting and forecasting accuracy for the different models used are shown in Table 2, and the monthly forecasts together with the actual catches for 1997 are shown in Figure 5. The X-11 method outperformed the other two methods, in terms of both fitting and forecasting performance, with respect to most measures used (Table 2). Thus, it captured the basic features of the study series (Fig. 5), with fits for 1982-1996 being highly correlated with the original data $\left(r^{2}=0.94\right)$, although they suffered from residual autocorrelation [Ljung-Box ${ }_{18-\text { dof }}$ $=98.57, \mathrm{P}>0.05]$ (Table 2). With the exception of October, November and December 1997, when the corresponding APE values were very high (as high as $178.6 \%$ ) because of the low level of the catches, monthly catches were predicted accurately, with a MAPE for the remaining nine months of $12.5 \%$. In contrast, the MAPE values of the ARIMA and WES models for all months excluding October-December were higher (ARIMA: 14.6\%; WES: 16.6\%; Table 2 ). The same was also true of the APE for the total annual catch (Table 2). All three methods performed better than the naive method, attaining $U$ values smaller than 1 (Table 2).

Consequently, the X-11 method was fitted to the catches of the 1982-1993, 1982-1994 and 19821995 periods and forecasts were built for 19941997, 1995-1997 and 1996-1997 and compared with those built for 1997 in Table 3. In general, the values of the maximum APE, MAPE and APE of the cumulative catch over the total forecasted period all increased, whereas those of $\mathrm{r}^{2}$ decreased with an increase in the forecasting horizon (Table 3). In addition, 12-month in advance forecasts (i.e. for the years 1994, 1995 and 1996) were also developed from the models fitted to each of the above-men-

TABLE 3. - Arithmetic values of the accuracy measures of the forecasting performance of the X-11 model used for forecasting monthly swordfish catches $12,24,36$ and 48 months in advance (i.e. fitting periods: 1982-1996, 1982-1995, 1982-1994 and 1982-1993 respectively; forecasts: 1997, 1996-1997, 1995-1997 and 19941997 respectively). APE: absolute percentage error; MAPE: mean APE; total APE: APE for the cumulative catch over the total forecasted period; $\mathrm{r}^{2}$ : coefficient of determination between forecast and actual catches.

\begin{tabular}{|c|c|c|c|c|c|}
\hline \multirow{2}{*}{$\begin{array}{l}\text { Forecast horizor } \\
\text { (months) }\end{array}$} & \multicolumn{5}{|c|}{ Accuracy measures } \\
\hline & APE min & APE max & MAPE & Total APE & $\mathrm{r}^{2}$ \\
\hline 12 & 3.8 & 178.6 & 31.8 & 1.40 & 0.95 \\
\hline 24 & 0.6 & 148.7 & 38.1 & 17.5 & 0.87 \\
\hline 36 & 0.6 & 213.9 & 58.0 & 32.2 & 0.71 \\
\hline 48 & 1.8 & 691.4 & 69.3 & 25.9 & 0.61 \\
\hline
\end{tabular}


tioned period. Although monthly forecasts had very high MAPE values for 1994 and 1995 (i.e. 119, 68 and $31 \%$ respectively) because of very large APE values $(>100 \%)$ of the forecasts for the months characterised by low catches (i.e. October to January), they captured the basic features of the monthly series, thereby explaining a large part of the variance of the actual catches during these periods $\left(\mathrm{r}^{2}=0.67\right.$, 0.56 and 0.90 , respectively). Indeed, when the monthly forecasts of the above-mentioned months were not taken into account, MAPE values were much lower (37.0, 42.1 and $12.8 \%$ for 1994, 1995 and 1996 respectively) being similar to the annual APE of the models $(36.7,32.5$ and $6.9 \%$ for 1994 , 1995 and 1996 respectively).

\section{DISCUSSION}

Forecasting plays a key role in fisheries management, since it precedes planning, which, in turn, precedes decision-making (Stergiou and Christou, 1996; Stergiou et al., 1997b). Apart from methods based on biological principles (e.g., Fox, 1970; Pope and Shepherd, 1985; Borges, 1990), a variety of statistical techniques have also been used for fisheries forecasting. These techniques are generally oriented towards (Stergiou and Christou, 1996; Stergiou et al., 1997b): (a) modelling on the basis of deterministic regression techniques that explain changes in fishery variables (e.g. catch, recruitment) in terms of changes in various biotic (e.g. spawning stock) and/or abiotic variables (e.g. fishing effort, climate); (b) modelling on the basis of univariate time series techniques that treat the system as a black box, viewed as an unknown generating process, and forecasting is based on projecting past values of a variable and/or past errors into the future; and (c) models that synthesise the above two general approaches (multivariate time series). Available studies indicate that although time series models do not have a built-in stock structure, they should not be dismissed (e.g. Stocker and Noakes, 1988; Noakes et al., 1990; Stergiou and Christou, 1996; Stergiou et al., 1997b; Lloret et al., 2000). This is especially true of cases for which time series of biological data (e.g. catchat-length or age) on various species are lacking, as is the case in Greek and Eastern Mediterranean waters in general, which renders the application of "biological" forecasting models impossible (with the exception of surplus-yield models; Stergiou et al., 1997b; Stergiou, 1998). In fact, time series models may pro- vide more accurate, short-term forecasts of various fisheries-related measures than "biological" models (e.g. Stoker and Noakes, 1988; Noakes et al., 1990; Stergiou and Christou, 1996; Stergiou et al., 1997b).

In the present study, three time series techniques were used to model and forecast the swordfish catches in Greek waters, using catch data reported by the NSSG for 1982-1997. Although the X-11 technique generally outperformed the ARIMA and WES models in terms of both fitting and forecasting performance (Table 2), its forecasting performance decreased with the length of the forecasting horizon (Table 3). The ARIMA and WES methods have generally been found to be efficient in forecasting fisheries catches in the largest comparison of methods ever used in fisheries forecasting (i.e. time-varying, harmonic, multiple and dynamic regression models; WES; ARIMA; and vector auto-regression) applied on the monthly NSSG catches of 16 species or groups of species in the Greek Seas during 19641989 (Engraulis encrasicolus; Sardina pilchardus; Boops boops; Pagellus erythrinus; Merluccius merluccius and Micromesistius poutassou; Trachurus spp.; Scomber spp.; Mullus spp.; Spicara spp.; total fish, cephalopods, crustaceans catches; and trawl, purse seine, beach seine and "other coastal boats" catches) (Stergiou et al., 1997b).

The overall good performance of X-11 in terms of short-term forecasting (i.e. up to 12 months in advance) and the fact that it provides an insight into the various components (i.e. the seasonal, trendcycle and irregular components) of the time series of interest both justify its use in fisheries research, along with simulation studies (e.g. Fromentin and Fonteneau, 2001). It must be pointed out, however, that since most International Commissions work with a delay of 6 to 12 months (i.e. stock assessments are performed with 6 to 12 month old data), short-term forecasting techniques will be useful only when such a delay is reduced considerably.

The increased variability observed after 1991 (Fig. 3d; the coefficient of variation was $115.7 \%$ and $258.4 \%$ before and after 1991) may indicate that swordfish has suffered overfishing in recent years, a fact that is also suggested by preliminary stock assessments carried out by ICCAT and the predominance of juveniles in the catches (Anonymous, 1996; ICCAT executive summaries of species status reports for 2000). The application of the X11 technique also showed that the monthly catches exhibit a clear seasonal pattern, with a major peak during the summer months (mainly in August) and a minor 
one during the winter months of 1982-1985 and of 1990-1997. The summer peak of the catches must be attributed to the higher fishing activity in summer, because of the prevailing favorable weather conditions (Tserpes, 1995; Tserpes et al., 1993). The minor winter peak could be related to the changes that have taken place in the Aegean swordfish fishery. In the early 1980s the fishery was opportunistic and mostly conducted by small coastal vessels operating in certain parts of the Aegean Sea (Fig. 1), which most probably represent feeding grounds (Tserpes and Peristeraki, 2000). The fishery started to expand from 1986 to the early 1990s because several boats that were previously involved in the sponge fishery gradually entered the swordfish fishery. These boats initially operated in the eastern Levantine but later expanded their activities throughout the southern Aegean Sea. Generally, since 1991, the fishery exploitation pattern has remained spatially stable. Thus, the absence of the winter peaks in the catches during 1986-1990 reflects the changes that took place in the exploitation pattern of the stock. Finally, the closed swordfish fishing season from October to January that was fully enforced after 1990 may be responsible for the re-appearance of the winter peak in the early 1990s, and the relatively higher catches obtained the first two months (February, March) following the reopening of the season.

As mentioned above, the $\mathrm{X}-11$ method provided accurate forecasts up to 12 months in advance (i.e. short-term, operational forecasts). This implies that forecasts were close to the actual reported catches. However, whether actual reported catches reflect real catches or not is a different matter. It is generally well known that catch statistics suffer from several biases, because of misreporting and underreporting (e.g. Watson and Pauly, 2001). Thus, the evaluation of the official catch statistics is essential for various fisheries analyses. Estimations of the swordfish catches have also been derived independently from research projects conducted during the last 15 years, based on the collection of detailed catch and effort data (i.e. annual number of hooks) from the main landing ports of the Aegean Sea (for details, see Anonymous, 1995; DeMetrio et al., 1992; Tserpes et al., 2000). Consequently, the total swordfish catches have been estimated through extrapolation to the total effort of the fleet, the latter being estimated through regular interviews with fishermen at all Greek landing sites. Such estimates are only available for the years for which the research pro-

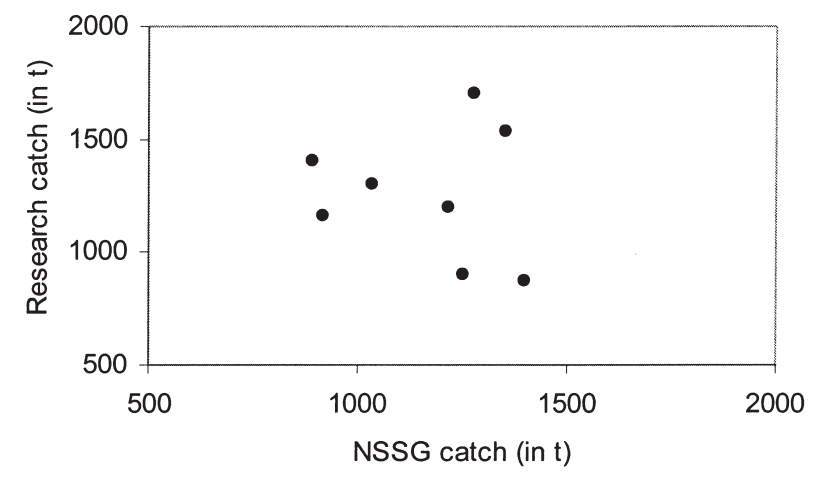

FIG. 6. - Relationship between the annual Greek catches of Xiphias gladius for the years 1986-1988 and 1990-1995 derived from two different sources, namely from NSSG and from survey estimates (Tserpes, unpublished data); the correlation coefficient between the two series is not significant $(r=0.51, n=8, P>0.2)$.

jects were conducted (i.e. 1986-1988 and 19901995; Tserpes, unpubl. data). There are important year-to-year differences between the NSSG and the research-survey time series (Fig. 6; r=0.51, $\mathrm{n}=8$, $\mathrm{P}>0.2$ ), with the research estimates differing from the NSSG reported catch values by 1.2 to $56.9 \%$ APE, depending on the year. However, their absolute percentage difference in terms of cumulative catches over the total period was only $10 \%$.

Although the seasonal resolution of the research survey series is limited when compared to the NSSG one, which justifies the use of the NSSG data for the requirements of the present study, the comparison between the two time series clearly revealed that the official reported catches might not actually reflect the real catches. This introduces 'subjective uncertainty' (uncertainty attributed to lack of knowledge: Ferson and Ginzburg, 1996) into various fisheries estimations, thereby seriously affecting the stock assessment of the Mediterranean swordfish. The observed patterns of temporal variability of both seasonal and long-term swordfish catches (Fig. 2) introduce "objective uncertainty" (i.e. uncertainties resulting from the underlying variability in stochastic processes, such as growth, mortality and recruitment: Ferson and Ginzburg, 1996) into various fisheries estimations. These two types of uncertainty should be treated separately in various risk analyses (Ferson and Ginzburg, 1996). Although it is widely recognised that objective uncertainty is one of the key-factors in predicting and managing fisheries resources (e.g. Walters and Maguire, 1996; Flaaten et al., 1998; Stokes et al., 1999; Cochrane, 2000), and managers are aware of such uncertainty, it is still largely neglected in stock assessment or management procedures (Lauck et al., 1998). In fact, it is to 
this aspect of fisheries ecology that recent paradigms of fish stocks collapses are generally attributed (e.g. Stergiou, 2002). This issue has also seriously hampered stock assessment of the Mediterranean swordfish in recent years (ICCAT executive summaries of species status reports for 2000).

\section{REFERENCES}

Anonymous. - 1995. Characterization of large pelagic stocks (Thunnus thynnus, Thunnus alalunga, Sarda sarda, and Xiphias gladius) in the Mediterranean. Final technical report of research project No XIV-1/ MED/ E, F, I, GR/91.

Anonymous. - 1996. International Commission for the Conservation of Atlantic Tunas (ICCAT). Collective volume of scientific papers. Vol. XLV(1) Madrid, Spain, 151 pp.

Anonymous. - 1999. International Commission for the Conservation of Atlantic Tunas (ICCAT). Collective volume of scientific papers. Vol. XLIX (1) Madrid, Spain, 530 pp.

Borges, M.F. - 1990. Multiplicative catch-at-age analysis of scad (Trachurus trachurus) from western Iberian waters. Fish. Res., 9: 333-353.

Box, G.E.P. and G.M. Jenkins. - 1976. Time series analysis, forecasting and control. Holden-Day, San Francisco.

Cochrane, K.L. - 2000. Reconciling sustainability, economic efficiency and equity in fisheries: the one that got away? Fish and Fisheries, 1: 3-21.

De Metrio, G. and P. Megalofonou. - 1987. Catch, size distribution, growth and sex ratio of swordfish (Xiphias gladius L.) in the Gulf of Taranto. FAO Fish. Rep., 394: 91-102.

De Metrio, G., P. Megalofonou, S. Tselas and N. Tsimenides. 1989. Fishery and biology of the swordfish Xiphias gladius, L., 1758 in Greek waters. FAO Fish. Rep., 412:135-145.

Di Natale, A. - 1990. Swordfish (Xiphias gladius L.) fishery in the southern Tyrrhenian Sea: A brief report (1985 - 1989). ICCAT, Collective volume of scientific papers. Vol. XXXIII, pp.135-139.

Durand, M.H. and R. Mendelsshon. - 1998. How to detect a change both on global and local scale in oceanographic time series. In: Durand M.H. et al. (eds) Global versus local changes in upwelling systems, ORSTOM, Paris, pp. 45-78.

Ferson, S., and L.R. Ginzburg. - 1996. Different methods are needed to propagate ignorance and variability. Reliab. Engineer. Syst. Saf., 54: 133-144.

Flaaten, O., A.G.V. Salvanes, T. Scweder and O. Ultang (eds). 1998. Objectives and uncertainties in fisheries management with emphasis on three North Atlantic Ecosystems: A selection of papers presented at an international symposium in Bergen, Norway, 3-5 June 1997. Fish. Res., 37: 1-310.

Fox, W.W. - 1970. An exponential surplus-yield model for optimising exploited fish populations. Trans. Am. Fish. Soc., 99: 80-88.

Fromentin, J-M., and A. Fonteneau. - 2001. Fishing effects and life history traits: a case study comparing tropical versus temperate tunas. Fish. Res., 53: 133-150.

Kotulas, G., A. Magoulas, N. Tsimenides and E. Zouros. - 1995. Marked mitochondrial DNA differences between Mediterranean and Atlantic populations of the swordfish, Xiphias gladius. Mol. Ecol., 4: 473-481.

Lauck T., C. Clark, M. Mangel and G.R. Munro. - 1998. Implementing the precautionary principle in fisheries management through marine reserves. Ecol. Applic. 8: 72-78.

Ljung, G.M. and G.E.P. Box. - 1978. On a measure of lack of fit in time series models. Biometrika, 67: 297-303.

Lloret, J., J. Leonat and I. Sole. - 2000. Time series modelling of landings in Northwest Mediterranean. ICES J. Mar. Sci., 57: 171-184.

Makridakis, S., S. Wheelwright and V. McGee. - 1983. Forecast- ing: methods and applications. John Wiley \& Sons, New York, $926 \mathrm{pp}$.

NSSG (National Statistical Service of Greece). - 1965-1999. Statistical Year-Book. 34 issues (for the years 1964-1997), Athens, Greece.

Noakes, D.J., D.W. Welch, M. Henderson and E. Mansfield. 1990. A comparison of preseason forecasting methods for returns of two British Columbia sockeye salmon stocks. N. Am. J. Fish. Manag., 10: 46-57.

Pope, J.G. and J.G. Shepherd. - 1985. A comparison of the perfomance of various methods for tuning VPAs using effort data. $J$. Cons. int. Explor. Mer, 42: 129-151.

Rey, J. C., E. Alot, A. Ramos and J.A. Caminas. - 1987. La pesqueria Española de pez espada con palangre en el Mediterraneo en 1985. ICCAT, Collective volume of scientific papers. Vol. XXVI (2).

Stellwagen, E.A. and R.L. Goodrich. - 1993. Forecast pro for windows. BFS Business Forecast Systems Inc., Belmont, MA, USA.

Stergiou, K.I. - 1998. Stock assessment in the eastern Mediterranean: problems and pitfalls. Hellenic Fish. News, 209: 147-151.

Stergiou, K.I. - 2000. Modelling and forecasting monthly anchovy catches using the X11 census technique. Proceedings of the 6th Panhellenic Oceanography and Fisheries Congress, 6(2): 170-174.

Stergiou, K.I. - 2002. Overfishing, tropicalization of fish stocks, uncertainty and ecosystem management: resharpening Ockham's razor. Fish. Res., 55: 1-9.

Stergiou, K.I. and E. Christou. - 1996. Modelling and forecasting annual fisheries catches: comparison of regression, univariate and multivariate time series methods. Fis. Res., 25: 103-138.

Stergiou, K.I., E. Christou, D. Georgopoulos, A. Zenetos and C. Souvermezoglou. - 1997a. The Hellenic Seas: physics, chemistry, biology and fisheries. Ocean. Mar. Biol. Ann. Rev., 35: 415-538.

Stergiou, K.I., E. Christou and G. Petrakis. - 1997b. Modelling and forecasting monthly fisheries catches: comparison of regression, univariate and multivariate time series methods. Fis. Res. 29: 55-95.

Stokes, T.K., D.S. Butterworth, R.L. Stephenson, and A.I.L. Payne. - 1999. Confronting uncertainty in the evaluation and implementation of fisheries-management systems. Introduction. ICES J. Mar. Sci., 56: 795-796.

Theil, H. - 1966. Applied economic forecasting. North-Holland Publishing Co., Amsterdam.

Tserpes, G. - 1995. "Greek swordfish fishery". In: International Commission for the Conservation of Atlantic Tunas (ICCAT). Collective volume of scientific papers. Vol. XLIV (1) Madrid, Spain, pp. 287-288.

Tserpes, G., and P. Peristeraki. - 2000. Indication for the existence of swordfish spawning areas in the eastern Mediterranean. Proceedings of the 6th Panhellenic Oceanography and Fisheries Congress, 6: 119-123.

Tserpes, G. and N. Tsimenides. - 1995. Determination of age and growth of swordfish, Xiphias gladius L., 1758, in the eastern Mediterranean using anal-fin spines. Fish. Bull., 93: 594-602.

Tserpes, G., P. Peristeraki and N. Tsimenides. - 1993. Greek swordfish fishery: some trends in the size composition of the catches. ICCAT, Collective volume of scientific papers. Vol. XL (1), pp. 137-140.

Tserpes, G., P. Peristeraki, C. Koutsikopoulos, G. De Metrio and A. Di Natale. - 2000. The swordfish fishery in the central and eastern Mediterranean Sea. Final report of Research Project No 97/046 (EU/DGXIV).

Tsimenides, N. and G. Tserpes. - 1989. Age determination and growth of swordfish Xiphias gladius L., 1758 in the Aegean sea". Fish. Res., 8: 159-168.

Walters, C., and J.J. Maguire. - 1996. Lessons for stock assessment from the northern cod collapse. Rev. Fish Biol. Fish., 6: 125-137.

Watson, R., and D. Pauly. - 2001. Systematic distortions in world fisheries catch trends. Nature, 414: 534-536.

Winters, P.R. - 1960: Forecasting sales by exponentially weighted moving averages. Manag. Sci., 6: 324-342. 